\title{
On the Desalination of Saline Waters via Batch Adsorption with Spent Tea Leaves
}

\author{
Kim $\mathbf{G}^{1}$, García $\mathbf{H}^{1}$, Japhe $\mathrm{T}^{\mathbf{1}}$, lyengar $\mathbf{R}^{1}$, Llanos $\mathrm{BP}^{\mathbf{2}}$ and Abel E Navarro ${ }^{\text {* }}$ \\ ${ }^{1}$ Science Department, Borough of Manhattan Community College, City University of New York, NY, USA \\ ${ }^{2}$ Sección Química, Departamento de Ciencias Exactas, Facultad de Ciencias y Filosofía, Universidad Cayetano Heredia, Lima-Perú
}

\begin{abstract}
Desalination is a technology that still needs to take off in scientific research. The current techniques are not appropriate and still demand great investments of money, manpower and space. This study proposes the use of spent tea leaves on the removal of sodium ions from seawater. Although our results do not show a remarkable purification of saltwater (maximum observed adsorption percentage of $8 \%$ ), but it demonstrates a strong effect of $\mathrm{pH}$, adsorbent mass, salt concentration, presence of other ions and dyes. This indicates that the desalination by using these materials could be tuned and optimized (base-treated GT reached $16 \%$ adsorption). Furthermore, column experiments demonstrate that this desalination technique could be taken to automatized systems for the purification of larger water volumes. Instrumental analyses demonstrated that these materials have high heat resistance and appropriate morphological and textural properties, indicating that have appropriate mechanical properties for their use as adsorbents. Lastly, the uptake of sodium ions was improved by the treatment of the tea leaves with diluted acid and bases, indicating their potential as desalinating biomaterials. These results create a new mindset on the desalination as a fertile area that will benefit the society.
\end{abstract}

Keywords: Desalination; Sodium chloride; Spent tea leaves, Chemical modification; Adsorption

\section{Introduction}

Large volumes of seawater from different sources have forced the scientific community to consider the possibility of their treatment and there is a growing interest in the development of studies and projects related to the utilization of difference desalination technologies $[1,2]$. Desalination could be defined as the process by which seawater that contains $35,000 \mathrm{ppm}$ of salt is converted into water that can be consumed by people, domestic applications and industrial utilization [3]. There are important differences between freshwater and potable water. The standards for freshwater can vary from country to country; however, the standard, accepted by the World Health Organization (WHO) identifies as freshwater as an aqueous solution that contains less than 500ppm of total dissolved solids (TDS) [4,5]. The definition of potable water would be basically the same, but also with the following properties: odorless, colorless, tasteless and also free of contaminating bacteria.

Salinity can change from ocean to ocean, but the relative proportions between the main components $\left(\mathrm{NaCl}, \mathrm{MgCl}_{2}, \mathrm{MgSO}_{4}, \mathrm{CaSO}_{4}, \mathrm{~K}_{2} \mathrm{SO}_{4}\right.$, $\mathrm{NaHCO}_{3}, \mathrm{LiBr}$ ) are practically constant for all the oceans $[2,5,6]$.

There is no doubt about the vital importance of water as a compound for life, and its use in any activity that are performed for our survival, such as industry, agriculture, livestock, and others. Likewise, water is a crucial factor in the development of a country. By the middle of the last century, lack of water resources have called the attention of societies, as their populations grow, and demands larger volumes of water for their activities. Recent reports indicate that the worldwide population in 2010 was more than 6,000 millions of people and keeps growing at rates of 80 million for year, and it has been predicted that this population could reach the number of 9,100 million by 2050 .

The Aral Sea is a clear example of the problematic that our planet suffers due to the inappropriate use of water resources, in the absence of a sustainable use of water and their impact in underground waters [7]. So, as a consequence of this problem, many solutions have been developed to make water more available in a short-term. Although freshwater cannot be directly obtained, it can be obtained by using man-made technologies. Desalination is seen as a viable technology that compensates the current disequilibrium in the water cycle and does not compete with other systems such as dams and channels [3-7].

The first desalination studies start in 1950, with the purpose of building big facilities for the production of freshwater. Good results were observed including the technology of flash distillation in multiple phases in 1957, which allows the installation of the first commercial plant in 1960 [8]. Today, desalinated water is utilized for human consumption, industrial processes and in a very limited manner for agricultural purposes.

There are many technologies to desalinate water, and although they are all different according to the energy source, design and production that each of them require, they are accomplishing the same goal: to reduce the concentration of dissolved sea salts. This allows us to distinguish between the processes that separate the water from the salt and the ones that really separate the salts from the water. For example: evaporation and crystallization separate water from salts, whereas membranes, exchange resins, and permeable membranes separate salts from water [8-10].

The availability of water does not imply that it could be used. The natural contamination and manhood have forced the inclusion of a pre-treatment step before human consumption, agriculture and industry [9].

"Corresponding author: Dr. Abel E Navarro, Science Department, Borough of Manhattan Community College, City University of New York, NY, USA, Tel: +01212-2208000; E-mail: anavarro@bmcc.cuny.edu

Received April 12, 2017; Accepted May 30, 2017; Published June 07, 2017

Citation: Kim G, García H, Japhe T, lyengar R, Llanos BP, et al. (2017) On the Desalination of Saline Waters via Batch Adsorption with Spent Tea Leaves. J Pet Environ Biotechnol 7: 326. doi: 10.4172/2157-7463.1000326

Copyright: (c) $2017 \mathrm{Kim} \mathrm{G}$, et al. This is an open-access article distributed under the terms of the Creative Commons Attribution License, which permits unrestricted use, distribution, and reproduction in any medium, provided the original author and source are credited. 
The most common techniques for desalination of seawater include: distillation, freezing, membrane processes, and reverse osmosis [10]. Although positive results have been obtained with these methodologies, the price of gallon of desalinated water cannot be afforded by the entire population.

On the other hand, biotechnology focuses on the search of new biological alternatives for different technological applications. The area of biotechnology that is in constant search of new materials for their application in environmental remediation is called biosorption [11-13]. As such, there have been recent studies that focus on the preparation and use of naturally-occurring materials in the purification of water from inorganic and organic pollutants. Conventional materials that used under this umbrella are algae, crustacean's shells, spent tea leaves, fruit peels, nutshells, eggshells, sawdust and others [12]. A more advance research has demonstrated that the adsorption efficiency of these materials can be improved by chemical modification by enriching the surface of these adsorbent with particular functional groups.

In this study, raw spent tea leaves of chamomile (CM), green tea (GT) and peppermint (PM) will be used as adsorbents of saltwater (synthetic seawater) as a potential alternative for the desalination of seawater. This study is preliminary and shows the beginning of a new avenue of research that needs to be explored. Spent tea leaves can be mass collected from industries such as Arizona, Snapple, Brisk and Nestea, which are big consumers of tea leaves. These companies will be more than favored by the use of their solid wastes (spent tea leaves) as desalinating materials. Salt is not a contaminant, but the scope of bioremediation has been adjusted as a new alternative for desalination.

\section{Materials and Methods}

\section{Conditioning of the adsorbents}

Green tea (GT), Peppermint (PM), and Chamomile (CM) were obtained from a local market. These tea samples were chosen based on the purity and homogeneity of their leaves, which include one single type of leaf and not a blend of herbs [11]. Teabags were vigorously boiled in tap water to discharge color, smell and taste, proper of the tealeaves. The last rinses were done with boiling distilled and deionized water to eliminate any chemical residues such as salts and other soluble substances. Then, teabags were oven-dried at no more than $50^{\circ} \mathrm{C}$, to prevent thermal decomposition, for at least $24 \mathrm{~h}$. Lastly, the teabags were cut open and the leaves were crushed and stored in plastic containers at room temperature until their use.

\section{Preparation and quantification of sodium ion solutions}

Sodium chloride $(\mathrm{NaCl})$ was purchased from Fisher Scientific (analytical grade, USA) and used without further purification. Stock solutions of $\mathrm{Na}$ (I) ions (1000 ppm) were made by dissolving the salt in deionized water and stored in the refrigerator until its use. This stock solution was weekly prepared. Adsorption experiments were carried out by dilution of the stock solution until reaching the desired concentrations. Initial and at equilibrium concentration of $\mathrm{Na}$ ions in the solution was quantified by ion selective electrode (Orion, Thermo Scientific), which is able to quantify concentration as low as ppb units. The electrode was coupled to a dual Benchtop meter meter (Orion Versa Star 40, Thermo Scientific). The electrode was daily calibrated before each sodium quantification. Samples required an ionic solution adjustor (ISA) to level the ionic strength. Glassware was carefully washed and rinsed with deionized water to prevent any contamination by external sodium ion sources. A control sample with plain deionized water was always used as a checkpoint to verify the absence of undesired $\mathrm{Na}$ ions.

\section{Adsorption experiments}

Batch experiments were performed at room temperature in an orbital shaker during an agitation time of at least $20 \mathrm{~h}$ (as determined by preliminary experiments). Runs were done in triplicates and the results were obtained by the average of their values. Batch experiments were run with a control sample (without adsorbent) to compare the initial versus the final concentration after the adsorption. Polyethylene plastic tubes were used for the batch experiments and sealed with parafilm to avoid any leakage. Plastic tubes did not report any adsorption of sodium. Several parameters were explored to optimize the adsorption of $\mathrm{Na}$ ions on the tealeaves, including initial solution $\mathrm{pH}$, adsorbent mass and initial sodium ion concentration. Moreover, the effect of interfering substances on the adsorption of sodium ions was also explored, using calcium ions, dyes and heavy metals as model species that are prevalent in saltwater.

\section{Continuous-flow experiments}

Cost efficiency is associated with the reduction of manpower and energy [12]. Therefore, a continuous system that could speed up the desalination process and to make it technologically competitive against reverse osmosis, freezing and distillation, is recommended to eliminate sodium ions from large volumes of seawater [12,13]. Batch experiments provided important parameters and optimization parameters that are needed to understand the uptake of sodium from solutions. However, in practice, continuous-flow (or column tests) are more applicable and closer to real conditions. For this test, columns of GT, CM and PM were packed in glass columns with dimensions $20 \mathrm{~cm} \times 0.7 \mathrm{~cm}$ for length and internal diameter, respectively. Sodium ion solution, at the optimum $\mathrm{pH}$, was pumped into the column against gravity with a peristaltic pump at a flow rate of $5 \mathrm{~mL} / \mathrm{min}$. Samples were collected with an automatic fraction collector; model CF-2 (Spectrum Labs).

\section{Characterization of the adsorbents}

The texture and morphology of the adsorbents was observed by Scanning electron microscopy (SEM), using a Table Top Microscopy, TM3000 (Hitachi). Samples were directly observed in the microscopy without any conductive gold film. Likewise, the heat resistance of the adsorbents was explored by thermal analysis, using a STA 6000 (Perkin Elmer) at a heat rate of $5^{\circ} \mathrm{C} / \mathrm{min}$ under a nitrogen atmosphere. Although these materials will not be utilized at high temperatures, but heat resistance resembles the mechanical and physical properties of the adsorbents.

\section{Statistical analysis of the results}

Sodium quantification was expressed as Adsorption Percentage (\%ADS) which follows the Equation (1):

$$
\% A D S=\frac{(C i-C e q) * 100}{C i}
$$

where $\mathrm{C}_{\mathrm{i}}$ and $\mathrm{C}_{\mathrm{eq}}$ are the initial and at equilibrium concentrations of sodium ions in the solutions. Mathematical and statistical treatment was done with excel (Microsoft) and Origin v5.0. A standard deviation was calculated and found to range between $3.3 \%$ to $3.8 \%$ in all the tests. Error bars were not added into the graphs to avoid overcrowding of curves.

\section{Results and Discussion}

\section{Effect of the $\mathrm{pH}$}

Seawater is subject to contamination and discharge of industrial and mining runoffs, which can alter the acidity conditions of the 
solution. Moreover, the increasing industrial activity and use of fossil fuels, constantly increase the concentration of $\mathrm{CO}_{2}$ in the atmosphere, which gets partially dissolved in the oceans, decreasing their $\mathrm{pH}$ [13]. Therefore, initial solution $\mathrm{pH}$ needs to be considered with any bioremediation approach to resemble the real conditions [11-13]. Prior research has demonstrated that $\mathrm{pH}$ has a strong effect on the removal of pollutants such as heavy metals $[14,15]$ and organic compounds [16-18]. According to these findings, the $\mathrm{pH}$ has a dual effect, on the chemistry of the adsorbate in solution and on the chemistry of the active adsorption sites on the surface of the biosorbent. The results for the effect of the $\mathrm{pH}$ on sodium removal are shown in Figure 1. From the results, the removal of sodium strongly depends on the $\mathrm{pH}$, with an irregular curve, due to the deprotonation of functional groups on the

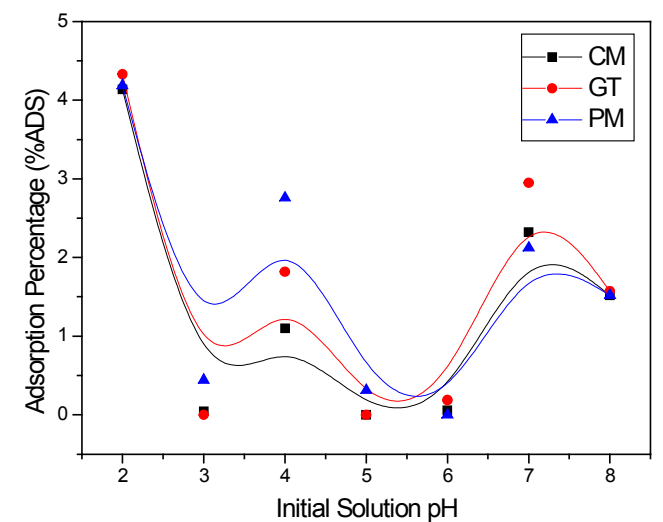

Figure 1: Effect of the $\mathrm{pH}$ on the adsorption of sodium ions from saltwater.

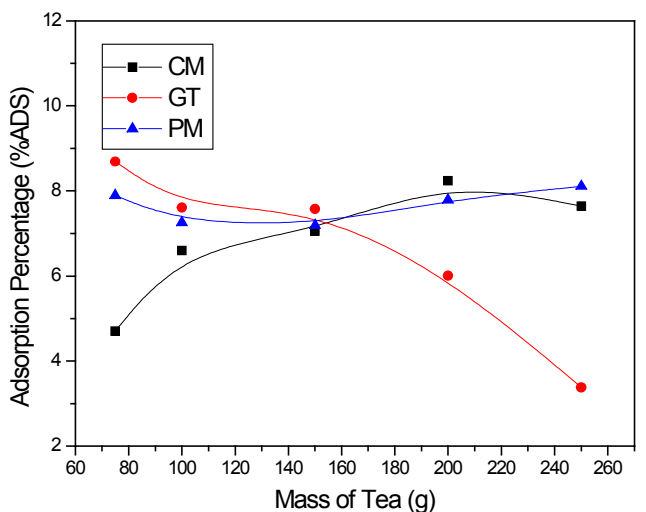

Figure 2: Effect of the mass of the adsorbent on the adsorption of sodium ions from saltwater. adsorbent. Surprisingly, the maximum adsorption is observed at low $\mathrm{pH}$ values (2) for all the adsorbents. We hypothesize an ionic exchange mechanism, where the adsorption sites need to be protonated (in the presence of excess hydronium ions) to occupy those sites. A relatively low adsorption is observed (4\%) for all the adsorbents, indicating that the materials share the same mechanisms towards sodium ions. The adsorption improves at neutral $\mathrm{pH}$, most likely due to the deprotonation of active sites that allows a better electrostatic interaction with sodium. According to these results, an optimum $\mathrm{pH}$ of 2 was observed, although a neutral $\mathrm{pH}$ has also a considerable sodium removal capacity. Finally, all the adsorbents show similar trends in sodium removal, therefore according to this effect, all tea leaves have similar affinities towards sodium.

\section{Effect of the adsorbent dose}

Figure 2 shows the effect of the adsorbent mass on the adsorption. A cost-effective technique should minimize material consumption therefore a maximum adsorption with the minimum mass of adsorbent is desired. According to the results, higher masses improved the adsorption of CM, whereas PM did not change the affinity towards sodium. Conversely, GT was greatly affected at increasing masses. This could be explained by aggregation problems in batch conditions. GT is the heaviest adsorbent and therefore sinks in the bottom of the tube, losing specific surface area to interact with sodium ions. On the other hand, CM is a very light adsorbent, which can be easily dispersed in the solution even at high masses of CM. According to these results, optimum masses of $150 \mathrm{mg}, 75 \mathrm{mg}$, and $75 \mathrm{mg}$ were chosen for CM, GT and $\mathrm{PM}$, respectively.

\section{Effect of presence of lead (II), calcium (II) and copper (II) ions}

Seawater is not an ideal sodium chloride solution. Besides sodium chloride, it can contain salts of calcium and perhaps other more toxic ions such as lead and copper divalent ions. The effect of these ions on the uptake are sodium is shown in Figure 3. The curves show that low concentrations of calcium and lead promote the binding of sodium, whereas copper favors the affinity of sodium towards the tea leaves at all studied concentrations. The mechanisms behind these scattered effects are unclear. However, it could be hypothesized that the smaller size of sodium ions facilitate their adsorption in the presence of $\mathrm{Ca}^{+2}$ and $\mathrm{Pb}^{+2}$, whereas at increasing concentrations of these two ions, the competition for the adsorption sites favors calcium and lead ions due to their higher Lewis acidity (mass/charge ratio). Apparently, since $\mathrm{Cu}$ ions do show this negative, we could conclude that copper and sodium ions do not compete for the same adsorption sites.

\section{Effect of the presence of dyes}

In the previous effect, inorganic impurities were tested on their
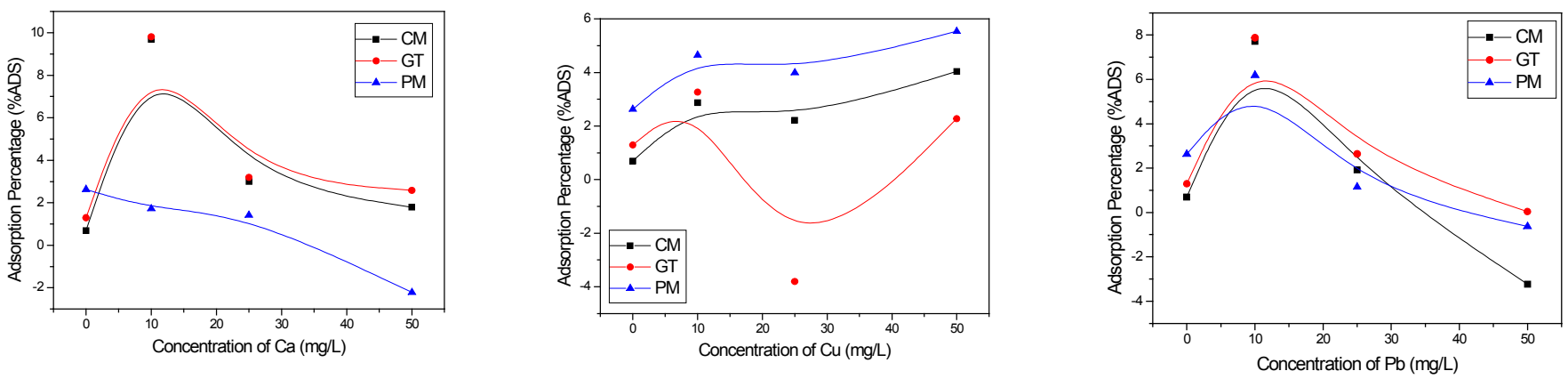

Figure 3: Effect of the presence of calcium (left), copper (middle) and lead (right) divalent ions on the adsorption of sodium ions from saltwater. 
role with the adsorption of sodium. However, real wastewaters also contain other organic and covalent impurities. For this test, a covalent compound, a dye Basic Yellow 54 (BY54) was added to the sodium solution to explore the effect on the adsorption. Dyes and other organic compounds have also been studied with tea leaves [17,18], showing a high affinity towards BY54. The results are shown in Figure 4. According to the experimental data, the presence of BY57 favors the adsorption of sodium for CM and GT, whereas PM adsorption is totally inhibited at high dye concentration. This result indicates that covalent impurities do not prevent the binding of sodium onto chamomile and green tea. Perhaps, this is because BY57 and sodium ions do not compete for the same adsorption sites. Furthermore, since an increasing adsorption is

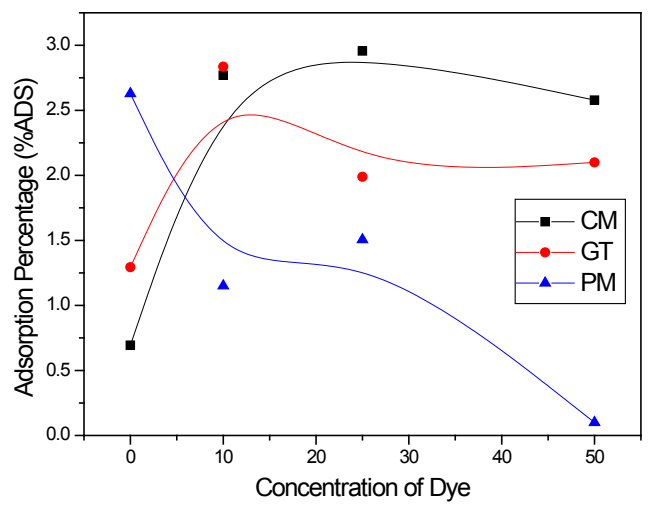

Figure 4: Effect of the presence dye Basic Yellow 54 on the adsorption of sodium ions from saltwater.

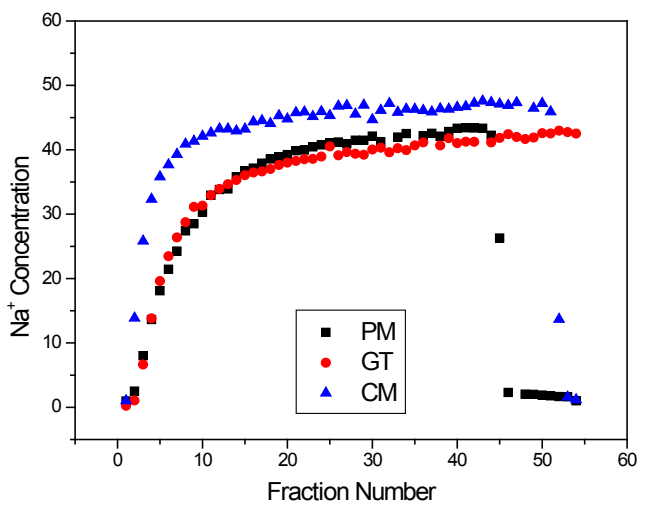

Figure 5: Column experiments with tea leaves for the uptake of sodium ions from saltwater. observed at higher BY57 concentration, we could conclude that teaadsorbed BY57 could serve as a new platform of adsorption sites for sodium ions. This effect is not observed with PM, which shows a lower adsorption at increasing BY57 concentrations. For this adsorbent, sodium and BY57 could be competing for the same active sites and the spatial orientation of the adsorbed BY57 does not allow sodium ions to be adsorbed (as hypothesized for CM and GT adsorption).

\section{Continuous-flow experiments}

The success of an alternative desalination process relies on the application of these techniques at larger scales to purify larger volumes of seawater. The competition with other conventional techniques needs to convince investors and governmental organization that adsorption minimizes costs and maximizes efficiency of the purification. A pilot experiment was run with the tea leaves. The preliminary results are shown in Figure 5. This data indicates that the process can be taken to medium- and big-scale and sodium can be quantified very efficiently. Although the purification of water is not achieved as indicated by the presence of sodium at early stages of the column, but saturation and exhausting points are clearly observed in the breakthrough curve. More studies are needed to optimize this method. Short-term adjustments include slower flow rates to maximize the contact between sodium and the adsorbent, as well as different column dimensions that will allow a better interaction between the adsorbent and adsorbate.

\section{Chemical conditioning of the adsorbents}

As observed from the previous data, the highest sodium ion adsorption reaches values of $3 \%$ (according to the $\mathrm{pH}$ effect) and $8 \%$ to $9 \%$ (according to the optimized mass effect). Although these are very encouraging results, it does not reach the minimum standards to compete with other available techniques. Therefore, a chemical conditioning of the adsorbents was tested to optimize the adsorption of these biomaterials. Since it is thought that the adsorption of sodium ions is mostly driven by the chemistry of the adsorbent and ionic exchange, the tea leaves were soaked in diluted acid (HCL) and base $(\mathrm{KOH})$ to explore the effect on the adsorption of sodium. The results are displayed in Figure 6. A new $\mathrm{pH}$ effect experiment was carried out with the native, acid-treated and base-treated tea samples. The new curves with the acid and base pre-treatment demonstrate that active functional groups need to be activated by the addition of acid and bases to enhance the uptake of sodium ions. For all the tea leaves, the adsorption of sodium ions is greatly increased by at least a factor of 2.5. Moreover, the maximum adsorption percentage is now observed at neutral $\mathrm{pH}$ values and not at acidic $\mathrm{pH}$ as it was observed in the first tests. These new chemically conditioned adsorbents promise to be
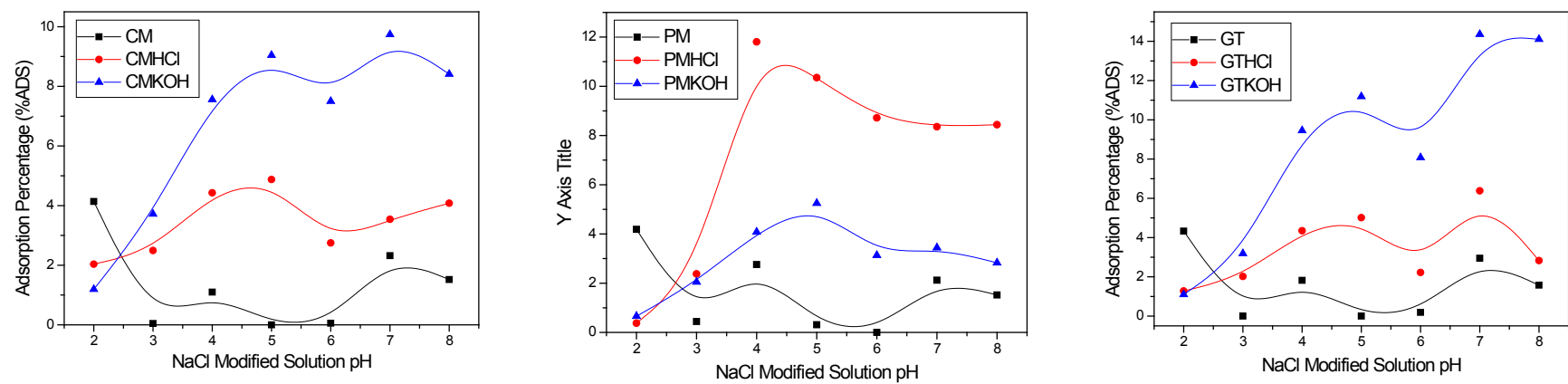

Figure 6: Effect of the pre-treatment of tea leaves on the uptake of sodium ions from saltwater. 
Citation: Kim G, García H, Japhe T, Iyengar R, Llanos BP, et al. (2017) On the Desalination of Saline Waters via Batch Adsorption with Spent Tea Leaves. J Pet Environ Biotechnol 7: 326. doi: 10.4172/2157-7463.1000326

more practical and close to experimental conditions; not only due to the increased adsorption, but also the working $\mathrm{pH}$ value. This experiment opens new alternatives and promises a better avenue in the use of these adsorbents for desalination. Further experiments need to be conducted with the pre-treated adsorbents to maximize the uptake of sodium to be used in continuous-flow tests.

\section{Characterization of the adsorbents}

The chemical, physical and mechanical properties of the adsorbents were explored by instrumental analyses. Thermal analyses were conducted with the three adsorbents to determine the heat resistance of the materials. The results are shown in Figure 7, showing that these adsorbents have a high heat resistance, and start decomposing at temperatures of $275^{\circ} \mathrm{C}$. Although the entire sample has similar cellulosic natures, $\mathrm{CM}$ shows the weakest resistance, because it is a flower, rather than a leaf, and it is expected to have softer fibers in its structure. It is important to mention that the purpose of this analysis is not to explore the potential use of these biomaterials at this high temperature (totally unrealistic), but to use the temperature resistance as an indicator of their thermal, mechanical and physical resistances as materials to be exposed to harsh experimental conditions. From Figure 7 , an initial mass loss of $\sim 2 \%$ to $3 \%$ is observed below $100^{\circ} \mathrm{C}$. This mass loss is attributes to the loss of water, indicating that $\mathrm{CM}$ shows higher water content in its structure due to its floral nature. As mentioned, thermal decomposition starts around $275^{\circ} \mathrm{C}$ and continues until $350^{\circ} \mathrm{C}$. Although the three adsorbents decompose around the same range, the mass loss follows the trend: $\mathrm{CM}>\mathrm{GT}>\mathrm{PM}$, indicating that PM is the most thermally, physically and mechanically stable of these biomaterials.

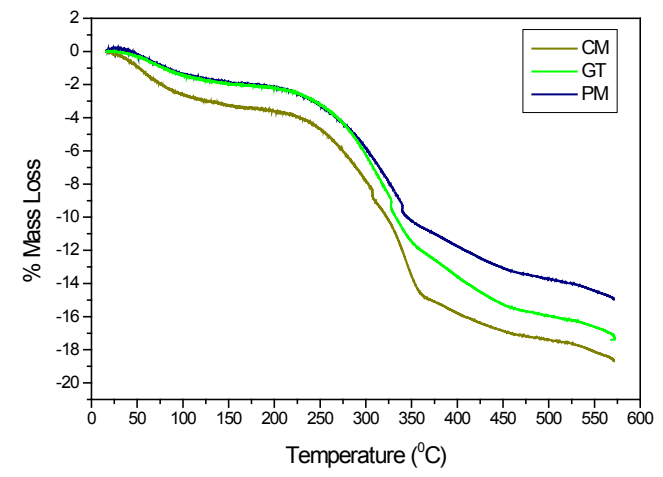

Figure 7: Thermal analysis of the adsorbents.
Lastly, the tea samples were observed under the scanning electron microscope to explore the morphological and textural properties of these materials. It was expected to observe pores, veins and fibrillary structures, as any plant-based material. The images are displayed in Figure 8. According to the figures, GT and PM show similar profiles, with vessels, pores and pockets that are good morphological properties for an adsorbent. These caves and holes can serve as complicated circuits where sodium ions travel and can get easily trapped in the interior adsorbent surface. Conversely, $\mathrm{CM}$ shows a more homogeneous surface, with pores and valleys, but not as elaborated as GT and PM. This difference in textural and morphology between the adsorbent could also explain the relatively smaller adsorption of CM, when compared to GT and PM.

\section{Conclusion}

Desalination is a technology that still needs to take off in scientific research. The current techniques are not appropriate and still demands great investments of money, manpower and space. This study proposes the use of spent tea leaves on the removal of sodium ions from seawater. Although our results do not show a remarkable purification of saltwater (maximum observed adsorption percentage of $8 \%$ ), but it demonstrates a strong effect of $\mathrm{pH}$, adsorbent mass, salt concentration, presence of other ions and dyes. This indicates that the desalination by using these materials could be tuned and optimized (base-treated GT reached 15\% adsorption). Furthermore, column experiments demonstrate that this desalination technique could be taken to automatized systems for the purification of larger water volumes. On the positive side, the uptake of sodium ions was improved by the treatment of the tea leaves with diluted acid and bases, indicating their potential as desalinating devices. Future work is on the works, since we consider this desalination project a fertile area that will benefit the society from any aspect.

\section{Acknowledgements}

This project was supported by the CRSP, CSTEP and BFF research programs and the Science Department at BMCC/CUNY. This work was supported by the C3IRG grant \#1224 (to A.E.N.) and INNOVATE-Peru, grant \# 169-PNICPECIP-2015 (to A.E.N.). Olga Kryvda and Chiu Hong Lee are acknowledged for the preliminary data and technical expertise.

\section{References}

1. Khawaji A, Kutubkhanah I, Wie JM (2008) Advances in seawater desalination technologies. Desalination 221: 47-69.

2. Lattermann S, Hopner T (2008) Environmental impact and impact assessment of seawater desalination. Desalination 220: 1-15.

3. Sadrzadeh M, Mohammadi T (2008) Sea water desalination using electrodialysis. Desalination 221: 440-447.
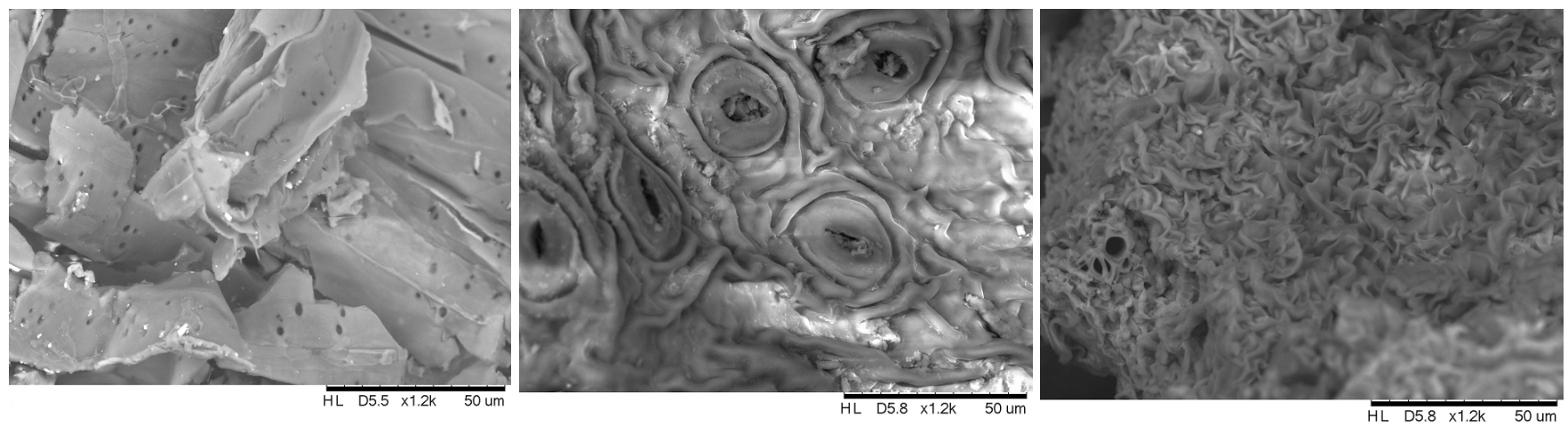

Figure 8: Scanning electron micrographs of CM (left), GT (middle) and PM (right) at 1200x magnification. 
Citation: Kim G, García H, Japhe T, lyengar R, Llanos BP, et al. (2017) On the Desalination of Saline Waters via Batch Adsorption with Spent Tea Leaves. J Pet Environ Biotechnol 7: 326. doi: 10.4172/2157-7463.1000326

4. Elimelech M, Phillip W (2011) The future of seawater desalination: Energy, technology and the environment. Science 333: 712-717.

5. Wang X, Ng K (2005) Experimental investigation of and adsorption desalination plant using low-temperature waste heat. Appl Thermal Engineering 25: 2780-2789.

6. McGinnis R, Elimelech M (2007) Energy requirements of ammonia-carbon dioxide forward osmosis desalination. Desalination 207: 370-382.

7. Fritzmann C, Lowenberg J, Wintgens T, Melin T (2007) State-of-the-art of reverse osmosis desalination. Desalination 216: 1-76.

8. Welgemoed T, Schutte C (2005) Capacitive deionization technology TM: An alternative desalination solution. Desalination 183: 327-340.

9. Alarcon-Padilla D, Garcia-Rodriguez L (2007) Application of absorption hea pumps to multi-effect distillation: a case study of solar desalination. Desalination 212: 294-302.

10. McCutcheon J, McGinnis R, Elimelech M (2005) A novel ammonia-carbon dioxide forward (direct) osmosis desalination process. Desalination 174: 1-11.

11. Japhe T, Zhdanova K, Rodenburg L, Roberson L, Navarro AE (2015) Factors affecting the Biosorption of 2-Chlorophenol using spent tea leaf wastes as adsorbents. J Environ Sci 1: 1-10.
12. Liu Y, Wang J (2009) Fundamentals and applications of biosorption isotherms, kinetics and thermodynamics. New York, Nova Science Publishers.

13. Volesky B (2004) Sorption and biosorption. BV Sorbex Inc., Quebec, Canada.

14. Choi Y, Isaac P, Irkakhujaev S, Masud ME, Navarro AE (2015) Use of spent tea wastes-chitosan capsules for the removal of divalent copper ions. J Environ Sci 1: 1-9.

15. Park R, Kim G, Shen L, Hong M, Navarro AE (2014) Batch adsorption of heavy metals onto chai tea residues for the bioremediation of contaminated solutions. Current Topics in Biotechnol 8: 51-62.

16. Sponza A, Fernandez N, Yang D, Ortiz K, Navarro AE (2015) Comparative sorption of methylene blue onto hydrophobic clays. Environments 2: 388-398.

17. Zarzar A, Hong M, Llanos B, Navarro AE (2015) Insights into the eco-friendly adsorption of caffeine from contaminated solutions by using hydrogel beads. $J$ Environ Anal Chem 2: 4

18. Japhe T, Paulsingh R, Ko K, Hong J, Navarro AE (2015) Bio-removal of antibiotics by using biodegradable hydrogel beads from aqueous solutions. $\mathrm{J}$ Environ Sci 1: 1-2. 